\title{
Complete genome sequence of the lignin- degrading bacterium Klebsiella sp. strain BRL6-2
}

\author{
Hannah L Woo ${ }^{1,2,3}$, Nicholas R Ballor ${ }^{1}$, Terry C Hazen 1,3,4,5, Julian L Fortney ${ }^{1,3}$, Blake Simmons ${ }^{1,6}$, \\ Karen Walston Davenport ${ }^{7}$, Lynne Goodwin ${ }^{7}$, Natalia Ivanova ${ }^{8}$, Nikos C Kyrpides ${ }^{8}$, Konstantinos Mavromatis ${ }^{8}$, \\ Tanja Woyke ${ }^{8}$, Janet Jansson ${ }^{9}$, Jeff Kimbrel ${ }^{1,10}$ and Kristen M DeAngelis ${ }^{11^{*}}$
}

\begin{abstract}
In an effort to discover anaerobic bacteria capable of lignin degradation, we isolated Klebsiella sp. strain BRL6-2 on minimal media with alkali lignin as the sole carbon source. This organism was isolated anaerobically from tropical forest soils collected from the Bisley watershed at the Ridge site in the El Yunque National Forest in Puerto Rico, USA, part of the Luquillo Long-Term Ecological Research Station. At this site, the soils experience strong fluctuations in redox potential and are characterized by cycles of iron oxidation and reduction. Genome sequencing was targeted because of its ability to grow on lignin anaerobically and lignocellulolytic activity via in vitro enzyme assays. The genome of Klebsiella sp. strain BRL6-2 is $5.80 \mathrm{Mbp}$ with no detected plasmids, and includes a relatively small arsenal of genes encoding lignocellulolytic carbohydrate active enzymes. The genome revealed four putative peroxidases including glutathione and DyP-type peroxidases, and a complete protocatechuate pathway encoded in a single gene cluster. Physiological studies revealed Klebsiella sp. strain BRL6-2 to be relatively stress tolerant to high ionic strength conditions. It grows in increasing concentrations of ionic liquid (1-ethyl-3-methyl-imidazolium acetate) up to $73.44 \mathrm{mM}$ and $\mathrm{NaCl}$ up to $1.5 \mathrm{M}$.
\end{abstract}

Keywords: Anaerobic lignin degradation, Tropical forest soil isolate, Facultative anaerobe

\section{Introduction}

Lignin is one of the biggest barriers to efficient lignocellulose deconstruction because it occludes the action of cellulases. It is also a major waste stream after lignocellulose deconstruction. Tropical forest soils are the sites of very high rates of decomposition, accompanied by very low and fluctuating redox potential conditions $[1,2]$. Because early stage decomposition is typically dominated by fungi and the free-radical generating oxidative enzymes phenol oxidase and peroxidase $[3,4]$, we targeted anaerobic tropical forest soils with the idea that they would be dominated by bacterial rather than fungal decomposers. Bacteria grow faster than fungi, allowing higher recombinant enzyme production for commercial use [5]. To discover organisms that were capable of breaking down lignin without the use of oxygen free radicals, we isolated Klebsiella sp. strain BRL6-2 under anaerobic conditions using lignin as the sole carbon

\footnotetext{
* Correspondence: kristen@post.harvard.edu

${ }^{11}$ Microbiology Department, University of Massachusetts, Amherst, MA, USA Full list of author information is available at the end of the article
}

source. In addition, this strain was observed to withstand moderately high concentrations of ionic liquids, and thus was targeted for whole genome sequencing.

\section{Organism information}

Klebsiella sp. strain BRL6-2 was isolated from soil collected from the Bisley watershed at the Ridge site in the El Yunque experimental forest, part of the Luquillo Long-Term Ecological Research Station in Luquillo, Puerto Rico, USA. A soil slurry was made with 1 gram of soil sample diluted in $100 \mathrm{ml}$ of MOD CCMA media without carbon source, serially diluted and inoculated to roll tubes containing MOD CCMA media with alkali lignin as the $\mathrm{C}$ source. MOD CCMA media consists of $2.8 \mathrm{~g} \mathrm{~L}^{-1} \mathrm{NaCl}, 0.1 \mathrm{~g} \mathrm{~L}^{-1} \mathrm{KCl}, 27 \mathrm{mM} \mathrm{MgCl}, 1 \mathrm{mM}$ $\mathrm{CaCl}_{2}, 1.25 \mathrm{mM} \mathrm{NH}_{4} \mathrm{Cl}, 9.76 \mathrm{~g} \mathrm{~L}^{-1} \mathrm{MES}, 1.1 \mathrm{ml} \mathrm{L}^{-1}$ filter sterilized $1 \mathrm{M} \mathrm{K}_{2} \mathrm{HPO}_{4}, 12.5 \mathrm{ml} \mathrm{L}^{-1}$ trace minerals [6,7], and $1 \mathrm{ml} \mathrm{L}^{-1}$ Thauer's vitamins [8]. Tubes were incubated at room temperature for up to 12 weeks, at which point the colony was picked from a roll tube that had been 
inoculated with a $10^{-4}$ dilution of soil slurry, grown in $10 \%$ tryptic soy broth (TSB), and characterized.

For initial genotyping and for validating the isolation, the small subunit ribosomal RNA gene was sequenced by Sanger sequencing using the universal primers $8 \mathrm{~F}$ and 1492R [9]. The 16S rRNA gene sequence places Klebsiella sp. strain BRL6-2 in the domain Bacteria, phylum Proteobacteria, class Gammaproteobacteria, and order Enterobacterales (Figure 1A). However, small subunit ribosomal RNA (16S rRNA) sequence is not sufficient to clearly define the evolutionary history of this region of the Gammaproteobacteria, so we have also constructed a hierarchical clustering of whole genomes based on pfams [10] (Figure 1B). This clustering supports the placement of Klebsiella sp. strain BRL6-2 within the order Enterobacterales.

A

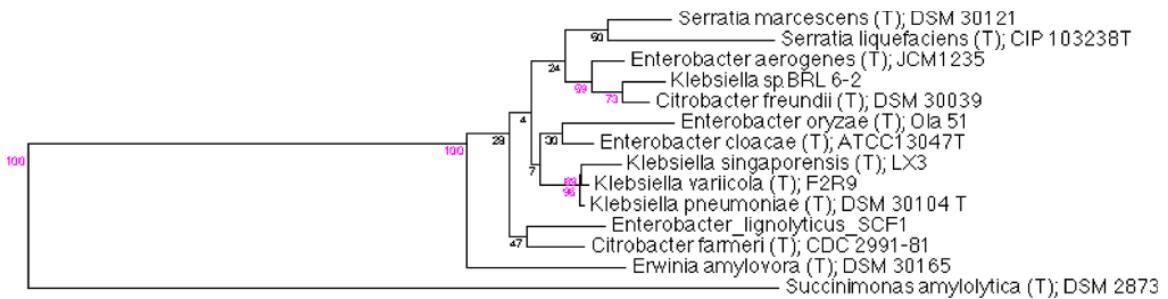

B

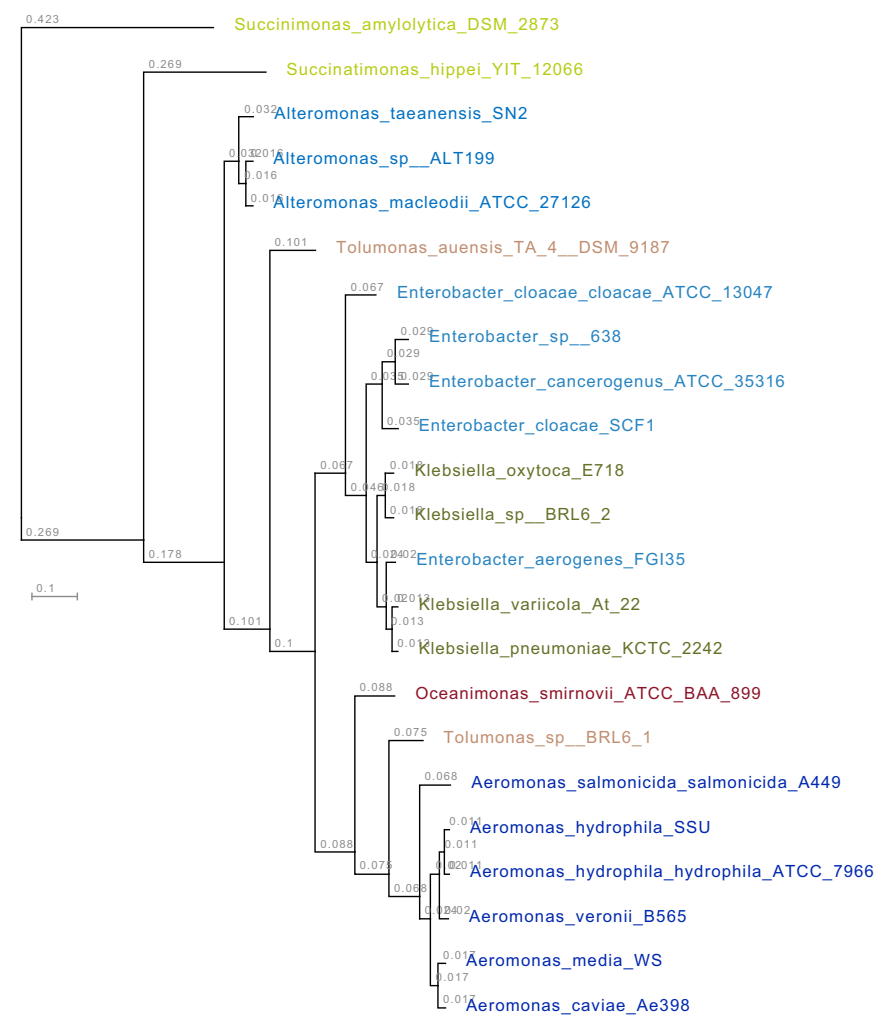

Figure 1 Phylogenetic trees highlighting the position of Klebsiella sp. strain strain BRL6-2 relative to other type and non-type strains within the Gammaproteobacteria, based on (A) 16S ribosomal RNA phylogeny, and (B) whole genome classification based on pfams. Strains are shown with corresponding NCBI genome project ids listed within [11]. The $16 \mathrm{~S}$ tree uses sequences aligned by the RDP aligner, the Jukes-Cantor corrected distance model to construct a distance matrix based on alignment model positions without the use of alignment inserts, and a minimum comparable position of 200. The tree is built with RDP Tree Builder, which uses Weighbor [12] with an alphabet size of 4 and length size of 1000. The building of the tree also involves a bootstrapping process repeated 100 times to generate a majority consensus tree [13]. The whole genome classification is a hierarchical clustering of pfams groups that was generated using the Integrated Microbial Genomes (IMG) system [14]. Succinimonas amylolytica DSM2873, Succinatimonas hippei YIT12066, and Tolumonas auensis TA 4 DSM9187 are type strains with genomes available in IMG. All others are non-type strains. 


\section{Genome sequencing information Genome project history}

The genome was selected based on the ability of Klebsiella sp. strain BRL6-2 to grown on and degrade lignin anaerobically (Table 1). The genome sequence was completed on 1 February 2013, and presented for public access on April 17, 2014 by Genbank. Finishing was completed at Los Alamos National Laboratory. A summary of the project information is shown in Table 2, which also presents the project information and its association with MIGS version 2.0 compliance [25].

\section{Growth conditions and DNA preparation}

Klebsiella sp. strain BRL6-2 grows well aerobically and anaerobically, and was routinely cultivated aerobically in $10 \%$ tryptic soy broth (TSB) with shaking at $200 \mathrm{rpm}$ at $30^{\circ} \mathrm{C}$. DNA for sequencing was obtained using the Qiagen Genomic-tip kit and following the manufacturer's instructions for the $500 / \mathrm{g}$ size extraction. Three column preparations were necessary to obtain $50 \mu \mathrm{g}$ of high molecular weight DNA. The quantity and quality of the extraction were checked by gel electrophoresis using JGI standards.

\section{Genome sequencing and assembly}

The draft genome of Klebsiella sp. strain BRL6-2 was generated at the DOE Joint genome Institute (JGI) using a hybrid of the Illumina and Pacific Biosciences (PacBio) technologies. An Illumina standard shotgun library and long insert mate pair library was constructed and sequenced using the Illumina HiSeq 2000 platform [26]. All general aspects of library construction and sequencing

Table 1 Classification and general features of Klebsiella sp. strain BRL6-2

\begin{tabular}{|c|c|c|c|}
\hline MIGS ID & Property & Term & ${\text { Evidence } \text { code }^{a}}^{a}$ \\
\hline & Current classification & Domain Bacteria & $\operatorname{TAS}[15]$ \\
\hline & & Phylum Proteobacteria & $\operatorname{TAS}[16]$ \\
\hline & & Class Gammaproteobacteria & $\operatorname{TAS}[17]$ \\
\hline & & Order Enterobacteriales & TAS[18] \\
\hline & & Family Enterobacteriaceae & $\operatorname{TAS}[19]$ \\
\hline & & Genus Klebsiella & $\operatorname{TAS}[20,21]$ \\
\hline & & Species Klebsiella sp. strain BRL6-2 & $\operatorname{TAS}[18,19,22]$ \\
\hline & Gram stain & negative & NAS \\
\hline & Cell shape & rod & IDA \\
\hline & Motility & motile via flagella & IDA \\
\hline & Sporulation & non-sporulating & IDA \\
\hline & Temperature range & Mesophile & IDA \\
\hline & Optimum temperature & $30^{\circ} \mathrm{C}$ & IDA \\
\hline & $\mathrm{pH}$ range; Optimum & $8-10 ; 8$ & IDA \\
\hline & Carbon source & glucose, xylose, others (Table 7) & IDA \\
\hline MIGS-6 & Habitat & Tropical forest soils & $\operatorname{TAS}[23]$ \\
\hline MIGS-6.3 & Salinity & $\begin{array}{l}\text { Can tolerate up to } 9 \% \mathrm{NaCl}, 6 \% \mathrm{KCl} \text {. Growth in } 10 \% \text { trypticase soy broth is improved } \\
\text { with } 0.125 \mathrm{M} \mathrm{NaCl}\end{array}$ & IDA \\
\hline MIGS-22 & Oxygen & facultative aerobe; grows well under completely oxic and anoxic conditions & IDA \\
\hline MIGS-15 & Biotic relationship & free-living & IDA \\
\hline MIGS-14 & Pathogenicity & no & \\
\hline MIGS-4 & Geographic location & $\begin{array}{l}\text { Soil collected from a subtropical lower montane wet forest in the Luquillo Experimental } \\
\text { Forest, part of the NSF- sponsored Long-Term Ecological Research program in Puerto Rico }\end{array}$ & IDA \\
\hline MIGS-5 & $\begin{array}{l}\text { Sample collection } \\
\text { time }\end{array}$ & July 2009 & IDA \\
\hline $\begin{array}{l}\text { MIGS-4.1 } \\
\text { MIGS-4.2 }\end{array}$ & Latitude - Longitude & $(18.268 \mathrm{~N}, 65.760 \mathrm{~W})$ & IDA \\
\hline MIGS-4.3 & Depth & $10 \mathrm{~cm}$ & IDA \\
\hline MIGS-4.4 & Altitude & 375 m & IDA \\
\hline
\end{tabular}

(a) Evidence codes - IDA: Inferred from Direct Assay; TAS: Traceable Author Statement (i.e., a direct report exists in the literature); NAS: Non-traceable Author Statement (i.e., not directly observed for the living, isolated sample, but based on a generally accepted property for the species, or anecdotal evidence). These evidence codes are from the Gene Ontology project [24]. 
Table 2 Project information

\begin{tabular}{lll}
\hline MIGS ID & Property & Term \\
\hline MIGS-31 & Finishing quality & Permanent draft \\
MIGS-28 & Libraries used & $\begin{array}{l}\text { Illumina Std PE, Illumina CLIP, } \\
\text { PacBio }\end{array}$ \\
MIGS-29 & Sequencing platforms & Illumina HiSeq 2000, PacBio \\
MIGS-31.2 & Fold coverage & Illumina Std PE 765x \\
& & Illumina CLIP PE 626x \\
& & PacBio 57x \\
MIGS-30 & Assemblers & AllpathsLG \\
MIGS-32 & Gene calling method & Prodigal 1.4, GenePRIMP \\
& Locus tag & G360 \\
& Genbank ID & ARVT00000000 \\
& Genbank Date of Release & April 17, 2014 \\
& GOLD ID & Gi0021863 \\
& BIOPROJECT & PRJNA185290 \\
& Project relevance & Anaerobic lignin, switchgrass \\
& & decomposition \\
MIGS-13 & Source Material Identifier & DSM 25465 \\
\hline
\end{tabular}

performed at the JGI can be found at http://www.jgi.doe. gov. All raw Illumina sequence data was passed through DUK, a filtering program developed at JGI, which removes known Illumina sequencing and library preparation artifacts [27]. Filtered Illumina and PacBio reads were assembled using AllpathsLG (PrepareAllpathsInputs: PHRED $64=1$ PLOIDY $=1$ FRAG COVERAGE $=125$ JUMP COVERAGE $=25$; RunAllpath- sLG: THREADS $=8 \mathrm{RUN}=$ standard pairs TARGETS $=$ standard VAPI WARN ONLY $=$ True OVERWRITE $=$ True) [28]. For the Std PE, 25,559,315 reads were generated as raw data, and 25,511,030 (99.811\%) reads were output after quality control. For the CLIP PE, 35,554,143 reads were generated as raw data, and $35,548,398$ (100\% but really 99.984\%) reads were output after quality control. A Pacbio SMRTbellTM library was constructed and sequenced on the PacBio RS platform. 81,950 raw PacBio reads yielded 105,417 adapter trimmed and quality filtered subreads totaling $294.3 \mathrm{Mb}$. The final draft assembly contains one contig in one scaffold. The total size of the genome is $5.8 \mathrm{Mb}$, and the final assembly provides an average 1199.1X Illumina coverage and 50.7X PacBio coverage of the genome, respectively.

\section{Genome annotation}

Genes were identified using Prodigal [29] as part of the DOE-JGI annotation pipeline [30] followed by a round of manual curation using the JGI GenePRIMP pipeline [31]. The predicted CDSs were translated and used to search the National Center for Biotechnology Information (NCBI) nonredundant database, UniProt, TIGRFam, Pfam, PRIAM, KEGG, COG, and InterPro databases. These data sources were combined to assert a product description for each predicted protein. Additional gene prediction analysis and manual functional annotation was performed within the Integrated Microbial Genomes (IMG-ER) platform (http://img.jgi.doe.gov/er) [32].

\section{Genome properties}

The genome consists of one 5,801,355 bp circular chromosome with no discernable plasmids, and a GC content of $55.24 \%$ (Table 3). Of the 5,495 genes predicted, 5,296 were protein-coding genes, and 199 RNAs; 64 pseudogenes were also identified. The majority of the protein-coding genes $(86.3 \%)$ were assigned with a putative function while the remaining ones were annotated as hypothetical proteins. The distribution of genes into COGs functional categories is presented in Table 4.

\section{Metabolic characterization using biolog phenotypic microarray}

The Biolog phenotypic microarray was used to test Klebsiella sp. strain BRL6-2's utilization of a variety of carbon, nitrogen, phosphorus, and sulfur sources. Different modifications of the isolation medium, MOD CCMA [33], were used to resuspend cells when inoculating different PM plates (Table 5). The scheme is similar to that used with D. vulgaris in S. Borglin et al. [34]. Plates were done iteratively to optimize each component before proceeding to the next. For all runs, a cell suspension at $0.1 \mathrm{OD}_{600}$ and Biolog redox Dye Mix G were used to inoculate the plates. All plates were prepared in duplicate, incubated at $30^{\circ} \mathrm{C}$, and read every 15 minutes

\section{Table 3 Genome statistics}

\begin{tabular}{lll}
\hline Attribute & Value & \% of Total $^{\mathbf{a}, \mathbf{b}}$ \\
\hline Genome size (bp) & $5,801,355$ & $100.00 \%$ \\
DNA coding region (bp) & $5,144,694$ & $88.68 \%$ \\
DNA G + C content (bp) & $3,204,653$ & $55.24 \%$ \\
DNA scaffolds & 1 & \\
Total genes & 5,495 & $100.00 \%$ \\
Protein-coding genes & 5,296 & $96.38 \%$ \\
RNA genes & 199 & $3.62 \%$ \\
Pseudo genes & 64 & $1.16 \%$ \\
Genes in internal clusters & NA & \\
Genes with function prediction & 4,740 & $86.26 \%$ \\
Genes assigned to COGs & 4,599 & $83.69 \%$ \\
Genes assigned Pfam domains & 4,904 & $89.24 \%$ \\
Genes with signal peptides & 582 & $10.59 \%$ \\
Genes coding for transmembrane helices & 1,330 & $24.20 \%$ \\
CRISPR repeats & NA &
\end{tabular}

a) The total is based on either the size of the genome in base pairs or the total number of protein coding genes in the annotated genome. b) Also includes 54 pseudogenes and 5 other genes. 
Table 4 Number of genes associated with general COG functional categories

\begin{tabular}{|c|c|c|c|}
\hline Code & Value & $\%$ of total ${ }^{a}$ & Description \\
\hline J & 204 & 3.92 & Translation \\
\hline A & 2 & 0.04 & RNA processing and modification \\
\hline K & 489 & 9.39 & Transcription \\
\hline $\mathrm{L}$ & 167 & 3.21 & Replication, recombination and repair \\
\hline B & 0 & 0 & Chromatin structure and dynamics \\
\hline D & 38 & 0.73 & Cell cycle control, mitosis and meiosis \\
\hline V & 61 & 1.17 & Defense mechanisms \\
\hline $\mathrm{T}$ & 213 & 4.09 & Signal transduction mechanisms \\
\hline M & 261 & 5.01 & Cell wall/membrane biogenesis \\
\hline N & 128 & 2.46 & Cell motility \\
\hline U & 178 & 3.42 & Intracellular trafficking and secretion \\
\hline $\mathrm{O}$ & 149 & 2.86 & $\begin{array}{l}\text { Post-translational modification, protein } \\
\text { turnover, chaperones }\end{array}$ \\
\hline C & 306 & 5.88 & Energy production and conversion \\
\hline G & 644 & 12.37 & Carbohydrate transport and metabolism \\
\hline $\mathrm{E}$ & 508 & 9.76 & Amino acid transport and metabolism \\
\hline $\mathrm{F}$ & 113 & 2.17 & Nucleotide transport and metabolism \\
\hline $\mathrm{H}$ & 207 & 3.98 & Coenzyme transport and metabolism \\
\hline । & 133 & 2.55 & Lipid transport and metabolism \\
\hline$P$ & 329 & 6.32 & Inorganic ion transport and metabolism \\
\hline Q & 138 & 2.65 & $\begin{array}{l}\text { Secondary metabolites biosynthesis, } \\
\text { transport and catabolism }\end{array}$ \\
\hline $\mathrm{R}$ & 533 & 10.24 & General function prediction only \\
\hline S & 405 & 7.78 & Function unknown \\
\hline- & 896 & 16.31 & Not in COGs \\
\hline
\end{tabular}

a) The total is based on the total number of protein coding genes in the annotated genome.
Table 5 Inoculation Fluid used for each PM plate type

\begin{tabular}{|c|c|c|}
\hline PM\# & Substrates on Plate & Inoculating Fluid \\
\hline 1 & Carbon sources & MOD CCMA \\
\hline 2 & Carbon sources & MOD CCMA \\
\hline 3 & Nitrogen sources & $\begin{array}{l}20 \mathrm{mM} \mathrm{Mannose} \mathrm{MOD} \mathrm{CCMA}_{\text {without } \mathrm{NH}_{4} \mathrm{Cl}}\end{array}$ \\
\hline 6 & Nitrogen sources & $\begin{array}{l}20 \mathrm{mM} \mathrm{Mannose} \mathrm{MOD} \mathrm{CCMA}_{\text {without } \mathrm{NH}_{4} \mathrm{Cl}}\end{array}$ \\
\hline 7 & Nitrogen sources & $\begin{array}{l}20 \mathrm{mM} \mathrm{Mannose} \mathrm{MOD} \mathrm{CCMA}_{\text {without } \mathrm{NH}_{4} \mathrm{Cl}}\end{array}$ \\
\hline 8 & Nitrogen sources & $\begin{array}{l}20 \mathrm{mM} \mathrm{Mannose} \mathrm{MOD} \mathrm{CCMA}_{\text {without } \mathrm{NH}_{4} \mathrm{Cl}}\end{array}$ \\
\hline 4 & Phosphorus and Sulfur sources & $\begin{array}{l}20 \mathrm{mM} \text { Mannose MOD CCMA } \\
\text { without } \mathrm{KH}_{2} \mathrm{PO}_{4} \text { or vitamins }\end{array}$ \\
\hline 9 & Osmolytes & 20 mM Mannose MOD CCMA \\
\hline 10 & $\mathrm{pH}$ & 20 mM Mannose MOD CCMA \\
\hline
\end{tabular}

for 4.5 days. PM1 and PM2 (carbon sources) were prepared anaerobically and aerobically to compare respiration. The anaerobic plates were prepared anaerobically in the anaerobic chamber in degassed medium and sealed in gas tight Whirlpak bags before loading into the Omnilog reader.

\section{Carbon sources}

190 different carbon substrates were tested using phenotypic microarray plates. The list of chemical additives that produced the highest increase in respiration relative to background is presented in Table 6. This was measured by the change in redox dye color. D-mannose was used in subsequent plates because of its convenient powder form compared to the viscous Tween solutions, which are mixtures of polyoxyethylene sorbitan esters of saturated fatty acids (predominantly 12:0, 14:0, and 16:0). They are typically used as a surfactant. Although the strain was isolated on lignin, D-cellobiose was utilized at almost the same rate as simpler carbohydrates glucose and xylose, which could suggest possible high cellulolytic activity as well.

\section{Anaerobic vs. aerobic carbon source utilization}

There were no significant differences between the aerobic and anaerobic utilization of the PM carbon sources. There is a vertical shift in the respiration curves, which is due to a difference in the starting $\mathrm{OL}$ at $\mathrm{t}=0$, as seen in negative control well A01.

\section{Nitrogen, phosphorus, and sulfur sources}

380 nitrogen sources were tested using phenotypic microarray plates. The most utilized nitrogen sources are reported in Table 7. Dipeptide amino acids were some of the most utilized sources, but ammonia from the original MOD CCMA was used in subsequent plates to avoid

Table 6 Carbon sources most utilized by Klebsiella sp. strain BRL6-2

\begin{tabular}{lll}
\hline Chemical Name & KEGG & Ratio to background \\
\hline Tween 20 & C11624 & 3.764 \\
Tween 40 & N/A & 3.573 \\
D-Mannose & C00159 & 3.678 \\
D-Ribose & C00121 & 3.425 \\
D-Fructose & C00095 & 3.602 \\
D-Trehalose & C01083 & 3.700 \\
N-Acetyl-D-Glucosamine & C03000 & 3.501 \\
D-Xylose & C00181 & 3.512 \\
Dulcitol & C01697 & 3.138 \\
a-D-Glucose & C00031 & 3.473 \\
D-Cellobiose & C00185 & 3.434 \\
Background & & 1
\end{tabular}


Table 7 Nitrogen sources most utilized by Klebsiella sp. strain BRL6-2

\begin{tabular}{ll}
\hline N source & Ratio to Background \\
\hline Gly-Asn & 2.867 \\
L-Cysteine & 2.835 \\
Gly-Gln & 2.766 \\
Allantoin & 2.758 \\
Urea & 2.749 \\
Ala-Arg & 2.677 \\
Ala-Gln & 2.650 \\
Thr-Arg & 2.634 \\
Trp-Ala & 2.631 \\
\hline
\end{tabular}

adding any other potential carbon source. Based on similar reasoning, phosphate was used for subsequent plates (Table 8). Within the sulfur wells, there was robust respiration in the negative control background well indicating that the buffer MES in the MOD CCMA media can serve as a possible sulfur source (Table 9). Since none of the other sulfur sources produced respiration significantly higher than background, MES will serve as the sulfur source in following plates.

\section{Osmolyte stress response}

Klebsiella sp. strain BRL6-2 was tested for respiration in a variety of osmolyte stressors and a range of $\mathrm{pH}$ (Table 10), with and without osmoprotectants (Table 11). For these assays, $20 \mathrm{mM}$ D-Mannose MOD CCMA was used to inoculate the osmolyte response assays in Omnilog PM plates 9 and 10. Klebsiella sp. strain BRL6-2 is relatively halotolerant as it grew in increasing concentrations of $\mathrm{NaCl}$ up to $9 \%$, which $1.5 \mathrm{M}$. The addition of trehalose,

Table 8 Phosphorus sources most utilized by Klebsiella sp. strain BRL6-2

\begin{tabular}{ll}
\hline P source & Ratio to Background \\
\hline Adenosine 2',3'-Cyclic Monophosphate & 1.877 \\
O-Phospho-D-Tyrosine & 1.732 \\
Thiophosphate & 1.736 \\
Tripolyphosphate & 1.810 \\
Phosphoenol Pyruvate & 1.733 \\
Cytidine 5'-Monophosphate & 1.671 \\
Pyrophosphate & 1.767 \\
Phosphate & 1.757 \\
Thymidine 5'-Monophosphate & 1.677 \\
Guanosine 2',3'-Cyclic Monophosphate & 1.686 \\
Guanosine 3'-Monophosphate & 1.668 \\
Phospho-Glycolic Acid & 1.634 \\
Background & 1 \\
\hline
\end{tabular}

Table 9 Sulfur sources most utilized by Klebsiella sp. strain BRL62

\begin{tabular}{ll}
\hline S source & Ratio to Background \\
\hline Tetramethylene Sulfone & 1.202 \\
Methane Sulfonic Acid & 1.122 \\
L-Methionine Sulfoxide & 1.139 \\
N-Acetyl-D,L-Methionine & 1.091 \\
L-Djenkolic Acid & 1.048 \\
L-Methionine Sulfone & 1.114 \\
2-Hydroxyethane Sulfonic Acid & 1.039 \\
L-Cysteine Sulfinic Acid & 1.090 \\
Gly-Met & 1.097 \\
L-Methionine & 1.072 \\
Taurocholic Acid & 1.020 \\
Thiourea & 1.019 \\
Taurine & 0.995 \\
Glutathione & 1.050 \\
D,L-Lipoamide & 1.002 \\
Hypotaurine & 1.007 \\
Butane Sulfonic Acid & 1.012 \\
N-Acetyl-L-Cysteine & 1.005 \\
1-Thio-b-D-Glucose & 0.966 \\
Background & 1 \\
p-Aminobenzene Sulfonic Acid & 0.993 \\
L-Cysteine & 1.018 \\
Sulfate & 0.990 \\
\hline & \\
\hline
\end{tabular}

Table 10 Osmolyte Stress Response of Klebsiella sp. strain BRL6-2

\begin{tabular}{ll}
\hline Assay Name & $\begin{array}{l}\text { Klebsiella sp. strain BRL6-2 } \\
\text { response }\end{array}$ \\
\hline $\mathrm{NaCl}$ Tolerance & Respiration up to 9\% (1.5 M) \\
$\mathrm{NaCl}$ Tolerance with various & $\begin{array}{l}\text { See next table for normalized area } \\
\text { under the curve }\end{array}$ \\
Potassium chloride & Respiration up to $6 \%$ \\
Sodium sulfate & Respiration up to $5 \%$ \\
Ethylene glycol & Respiration up to $20 \%$ \\
Sodium formate & Respiration up to $2 \%$ \\
Urea & Respiration up to $7 \%$ \\
Sodium lactate & Longer lag phase with addition of \\
Sodium lactate up to $12 \%$ but \\
Sodium phosphate & roughly same final yield. \\
Sodium benzoate & Respiration in $20-200 \mathrm{mM}$ \\
Ammonium sulfate & No respiration \\
Sodium nitrate & Respiration in $10-100 \mathrm{mM}$ \\
& Respiration up to $20 \mathrm{mM}$ \\
& Respiration up to $40 \mathrm{mM}$ \\
&
\end{tabular}


Table 11 Osmoprotectants utilized by Klebsiella sp. strain BRL6-2 in response to $\mathrm{NaCl}$ stress

\begin{tabular}{ll}
\hline Osmoprotectant & $\begin{array}{l}\text { Ratio to } \mathrm{NaCl} \text { 6\% without } \\
\text { osmoprotectant }\end{array}$ \\
\hline $\mathrm{NaCl} 6 \%$ & 1 \\
$\mathrm{NaCl} 6 \%+\mathrm{KCl}$ & 0.968 \\
$\mathrm{NaCl} 6 \%+$ Creatine & 1.011 \\
$\mathrm{NaCl} 6 \%+$ N-acethyl L-glutamine & 1.031 \\
$\mathrm{NaCl} 6 \%+$ Sarcosine & 1.044 \\
$\mathrm{NaCl} 6 \%+$ L-Carnitine & 1.052 \\
$\mathrm{NaCl} 6 \%+$ MOPS & 1.121 \\
$\mathrm{NaCl} 6 \%+$ Creatinine & 1.131 \\
$\mathrm{NaCl} 6 \%+$ gamma-amino-n-butyric acid & 1.145 \\
$\mathrm{NaCl} 6 \%+$ B-glutamic acid & 1.150 \\
$\mathrm{NaCl} 6 \%+$ Glutathione & 1.154 \\
$\mathrm{NaCl} 6 \%+$ L-proline & 1.166 \\
$\mathrm{NaCl} 6 \%+$ Trigonelline & 1.195 \\
$\mathrm{NaCl} 6 \%+$ Phosphoryl choline & 1.204 \\
$\mathrm{NaCl} 6 \%+$ Betaine & 1.240 \\
$\mathrm{NaCl} 6 \%+$ Dimethyl sulphonyl proprionate & 1.262 \\
$\mathrm{NaCl} 6 \%+$ Choline & 1.285 \\
$\mathrm{NaCl} 6 \%+$ Trimethylamine & 1.329 \\
$\mathrm{NaCl} 6 \%+$ N-N Dimethyl glycine & 1.329 \\
$\mathrm{NaCl} 6 \%+$ Ectoine & 1.333 \\
$\mathrm{NaCl} 6 \%+$ Trimethylamine-N-oxide & 1.355 \\
$\mathrm{NaCl} 6 \%+$ Octopine & 1.365 \\
$\mathrm{NaCl} 6 \%+$ Glycerol & 1.371 \\
$\mathrm{NaCl} 6 \%+$ Trehalose & 1.371 \\
\hline & \\
\hline
\end{tabular}

glycerol, octopine, and trimethylamine- $\mathrm{N}$-oxide aided respiration in presence of $6 \% \mathrm{NaCl}$. The strain was found to be particular sensitive to sodium benzoate out of all the osmolytes tested. Klebsiella sp. strain BRL6-2 was found

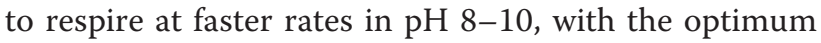
at $\mathrm{pH} 8$.

\section{Lignocellulose degradation}

Because Klebsiella sp. strain BRL6-2 was initially isolated based on colony formation on minimal media with lignin supplied as the sole carbon source [35], we examined the genome to search for genes encoding putative proteins that would be associated with lignin degradation. It has a full protocatechuate pathway for processing catechol degradation to $\beta$-ketoadipate, as in Cupriavidus basilensis OR16 and Sphingomonas paucimobilis SYK6 [36,37]. It has six putative peroxidase genes, encoding for glutathione peroxidases, DyP-type peroxidases, and catalases/peroxidases; all are potentially important for lignin degradation $[38,39]$. It has two putative lactate dehydrogenase genes (EC:1.1.1.28) and two putative catalase genes (EC:1.11.1.6), and no laccase genes. It also has multiple cytochrome oxidase genes suggesting the possible use of lignin as a terminal electron acceptor as was previously observed for a related isolate Enterobacter lignolyticus SCF1 [40]. For the degradation of other relevant lignocellulose components like xylan and cellulose, Klebsiella sp. strain BRL6-2 has 2 xylanase genes, $6 \beta$ xylosidase genes, $12 \beta$-glucosidase genes, and 2 endoglucanase genes.

Upon isolation of the strain on lignin, Klebsiella sp. strain BRL6-2's ability to degrade several lignocellulose analogs in vitro was measured. Using a 4-methylumbelliferone based enzyme assay that has been previously used on bacterial isolates [35], cells grown in MOD CCMA plus $20 \mathrm{mM}$ Mannose had high levels of $\beta$-glucosidase and xylosidase activity with $80 \%$ and $28 \%$ of the given substrate being degraded within 45 hours. However, it had low activity of cellobiohydrolase. Klebsiella sp. strain BRL6-2 was also tested for CMCase, another important class of cellulase, using a reducing sugar detection assay with 3,5-dinitrosalicylic acid (DNS) reagent and CMC [41]. No activity was detected on CMC. These low activities of cellulases could not be improved by growing cells in MOD CCMA plus $20 \mathrm{mM}$ Mannose supplemented with $0.1 \%$ CMC. Although cellulose was a well-utilized substrate from the phenotypic microarray measurements, it may be due to Klebsiella sp. strain BRL6-2's effective $\beta$-glucosidase.

\section{Ionic liquid tolerance}

Currently, ionic liquids are being investigated for their application to the bioenergy feedstock pretreatment; one of which is 1-ethyl-3-methyl-imidazolium acetate (Emim-Acetate). Klebsiella sp. strain BRL6-2 was tested for growth in $20 \mathrm{mM}$ Mannose MOD CCMA in the presence of $0 \mathrm{mM}, 36.72 \mathrm{mM}, 73.44 \mathrm{mM}, 146.88 \mathrm{mM}$, $293.75 \mathrm{mM}, 587.51 \mathrm{mM}$ Emim-Acetate. A 6\% inoculum concentration from a $0.4 \mathrm{OD}_{600}$ cell suspension was used to inoculate each treatment. Biolog Dye Mix G was used to monitor cell respiration during the incubation at $30^{\circ} \mathrm{C}$ within a Biolog reader. Klebsiella sp. strain BRL6-2 could tolerate up to $73.44 \mathrm{mM}$ Emim-Acetate with increased lag phase and decreased final yields with increasing concentrations of Emim-Acetate. This is not as ionic liquid tolerant as Enterobacter lignolyticus SCF1, which was isolated in the same screen and showed tolerance of up to $500 \mathrm{mM}$ 1-ethyl-3-methyl-imidazolium chloride [42]. However, Klebsiella sp. strain BRL6-2 tolerates ionic liquid concentrations higher than most bacterial strains, including $E$. coli, which were highly sensitive to concentrations as low as $14.69 \mathrm{mM}$. Klebsiella sp. strain BRL6-2 has 1,107 genes classified as protein coding genes connected to transporters, and these transporters 
are likley the source of resistance to high ionic strenght, as was also observed in E. lignolyticus SCF1 [42].

\section{Conclusion}

Klebsiella sp. strain BRL6-2 is an "Enterobacterales" in the order Gammaproteobacteria, originally isolated based on its ability to grow on lignin as sole carbon source under anaerobic conditions. Its ability to degrade lignin likely has origins in its full protocatechuate pathway, six putative peroxidase genes, two putative lactate dehydrogenase genes, and two putative catalase genes. It also has multiple cytochrome oxidase genes, suggesting the possibility of dissimilatory as well as assimilatory lignin degradation pathways. We also observed high tolerance of ionic strenght conditions, likely facilitated by its many transporter classified genes. Future experiments with Klebsiella sp. strain BRL6-2 should assess its growth kinetics on purified lignin compounds aerobically and anaerobically to determine the extent of its lignin-degrading potential. However, its fast growth, facultative lifestyle, and tolerance to high ionic strength conditions make it an attractive microbial host to bioengineer for industrial lignocellulose degradation and consolidated bioprocessing of biofuels.

\section{Competing interests}

The authors declare that they have no competing interests.

\section{Authors' contributions}

$H L W, N R B$, and JLF performed the microbiology and molecular biology studies; KFD, LG, NI, KCK, KM, JK, JJ and TW performed the sequencing and annotation; HLW, KMD performed the genomic analysis; HLW, TCH, BAS and KMD wrote the manuscript.

\section{Acknowledgements}

The work conducted in part by the U.S. Department of Energy Joint Genome Institute and in part by the Joint BioEnergy Institute, and is supported by the Office of Science of the U.S. Department of Energy Under Contract No. DE-ACO2-05CH11231.

\section{Author details}

'Microbial Communities Group, Deconstruction Division, Joint BioEnergy Institute, Emeryville, CA, USA. ${ }^{2}$ Physical Biosciences Division, Lawrence Berkeley National Laboratory, Berkeley, CA, USA. ${ }^{3}$ Department of Civil \& Environmental Engineering, The University of Tennessee, Knoxville, TN, USA. ${ }^{4}$ Department of Microbiology, The University of Tennessee, Knoxville, TN, USA. ${ }^{5}$ Department of Earth \& Planetary Sciences, The University of Tennessee, Knoxville, TN, USA. ${ }^{6}$ Sandia National Lab, Livermore, CA, USA. ${ }^{7}$ Los Alamos National Laboratory, Los Alamos, NM, USA. ${ }^{8}$ Department of Energy Joint Genome Institute, Walnut Creek, CA, USA. 'Biological Sciences Division, Pacific Northwest National Laboratory, Richland, WA, USA. ${ }^{10}$ Lawrence Berkeley National Laboratory, Berkeley, CA, USA. ${ }^{11}$ Microbiology Department, University of Massachusetts, Amherst, MA, USA.

Received: 21 May 2014 Accepted: 3 November 2014

Published: 8 December 2014

\section{References}

1. Cusack DF, Chou WW, Yang WH, Harmon ME, Silver WL. Controls on longterm root and leaf litter decomposition in neotropical forests. Glob Chang Biol. 2009; 15:1339-55.

2. Parton W, Silver WL, Burke IC, Grassens L, Harmon ME, Currie WS, King JY, Adair EC, Brandt LA, Hart SC, Fasth B. Global-scale similarities in nitrogen release patterns during long-term decomposition. Science. 2007; 315:361.
3. Freeman C, Ostle N, Kang H. An enzymic "latch" on a global carbon store. Nature. 2001; 409:149-49.

4. Paul EA, Clark FE. Soil microbiology, ecology, and biochemistry. New York, NY: Academic Pr; 1996

5. Maki M, Leung KT, Qin W. The prospects of cellulase-producing bacteria for the bioconversion of lignocellulosic biomass. Int J Biol Sci. 2009; 5:500-16.

6. Tschech A, Pfennig N. Growth yield increase linked to caffeate reduction in Acetobacterium woodii. Arch Microbiol. 1984; 137:163-67.

7. Widdel F, Kohring GW, Mayer F. Studies on dissimilatory sulfate-reducing bacteria that decompose fatty acids. Arch Microbiol. 1983; 134:286-94.

8. Janssen PH, Schuhmann A, Morschel E, Rainey FA. Novel anaerobic ultramicrobacteria belonging to the Verrucomicrobiales lineage of bacterial descent isolated by dilution culture from anoxic rice paddy soil. Appl Environ Microbiol. 1997; 63:1382.

9. Wilson $\mathrm{KH}$, Blitchington RB, Greene RC. Amplification of bacterial $16 \mathrm{~S}$ ribosomal DNA with polymerase chain reaction. J Clin Microbiol. 1990; 28:1942-46.

10. Bateman A. The Pfam protein families database. Nucleic Acids Res. 2004 32:138D-141.

11. Garrity GM, Lilburn TG, Cole JR, Harrison SH, Euzeby J, Tindall BJ. Introduction to the Taxonomic Outline of Bacteria and Archaea (TOBA) Release 7.7. The Taxonomic Outline of Bacteria and. Archaea. 2007; 7:1-5

12. Bruno WJ, Socci ND, Halpern AL. Weighted Neighbor Joining: A Likelihood-Based Approach to Distance-Based Phylogeny Reconstruction. Mol Biol Evol. 2000; 17:189-97.

13. Cole JR, Wang Q, Cardenas E, Fish J, Chai B, Farris RJ, Kulam-Syed-Mohideen AS, McGarrell DM, Marsh T, Garrity GM, Tiedje JM. The Ribosomal Database Project: improved alignments and new tools for rRNA analysis. Nucleic Acids Res. 2009; 37:D141-5. Available at: http://www.nar.oxfordjournals.org/ cgi/doi/10.1093/nar/gkn879. Accessed April 5, 2012.

14. Markowitz VM, Chen I-MA, Palaniappan K, Chu K, Szeto E, Grechkin Y, Ratner A, Jacob B, Huang J, Williams P, Huntemann M, Anderson I, Mavromatis K, Ivanova NN, Kyrpides NC. IMG: the Integrated Microbial Genomes database and comparative analysis system. Nucleic Acids Res. 2012; 40: D115-22. doi:10.1093/nar/gkr1044.

15. Garrity GM, Holt JG. Taxonomic Outline of the Archaea and Bacteria. In: Garrity GM, Boone DR, Castenholz RW, editors. Bergey's Manual of Systematic Bacteriology, Second Edition, Volume 2, Part B. 2nd ed. New York: Springer; 2001.

16. Garrity GM, Bell JA, Lilburn T, Phylum XIV. Proteobacteria phyl. In: Garrity GM, Brenner DJ, Krieg NR, Staley JT, editors. Bergey's Manual of Systematic Bacteriology, Second Edition, Volume 2, Part B. 2nd ed. New York: Springer; 2005.

17. Garrity GM, Bell JA, Lilburn T. Class III. Gammaproteobacteria class. In: Garrity GM, Brenner DJ, Krieg NR, Staley JT, editors. Bergey's Manual of Systematic Bacteriology, Second Edition, Volume 2, Part B. 2nd ed. New York: Springer; 2005

18. Skerman VBD, McGowan V, Sneath PHA. Approved Lists of Bacterial Names. Int J Syst Bacteriol. 1980; 30:225-420.

19. Commission J. Conservation of the family name Enterobacteriaceae, of the name of the type genus, and designation of the type species OPINION NO. 15. Int Bull Bacteriol Nomend Taxon. 1958; 8:73-4.

20. Brisse $S$, Grimont F, Grimont PAD. The Genus Klebsiella. In: Dr MDP, Falkow S, Rosenberg E, Schleifer K-H, Stackebrandt E, editors. The Prokaryotes. New York: Springer; 2006: p. 159-96.

21. Drancourt M, Bollet C, Carta A, Rousselier P. Phylogenetic analyses of Klebsiella species delineate Klebsiella and Raoultella gen. nov., with description of Raoultella ornithinolytica comb. nov., Raoultella terrigena comb. nov. and Raoultella planticola comb. nov. Int J Syst Evol Microbiol. 2001; 51:925-32.

22. Rahn O. New principles for the classification of bacteria. Zentralblatt für Bakteriologie, Parasitenkunde, Infektionskrankheiten und Hygiene Abteilung II. 1937; 96:273-86.

23. DeAngelis KM, Silver WL, Thompson AW, Firestone MK. Microbial communities acclimate to recurring changes in soil redox potential status. Environ Microbiol. 2010; 12:3137-49.

24. Ashburner M, Ball CA, Blake JA, Botstein D, Butler H, Cherry JM, Davis AP, Dolinski K, Dwight SS, Eppig JT, Harris MA, Hill DP, Issel-Tarver L, Kasarskis A, Lewis S, Matese JC, Richardson JE, Ringwald M, Rubin GM, Sherlock G. Gene 
ontology: tool for the unification of biology. The Gene Ontology Consortium. Nat Genet. 2000; 25:25-9.

25. Field D, Garrity G, Gray T, Morrison N, Selengut J, Sterk P, Tatusova T, Thomson N, Allen MJ, Angiuoli SV, Ashburner M, Axelrod N, Baldauf S, Ballard S, Boore J, Cochrane G, Cole J, Dawyndt P, Vos PD, dePamphilis C, Edwards R, Faruque N, Feldman R, Gilbert J, Gilna P, Glöckner FO, Goldstein $P$, Guralnick R, Haft D, Hancock D, et al. The minimum information about a genome sequence (MIGS) specification. Nat Biotechnol. 2008; 26:541-7.

26. Bennett S, Solexa Ltd. Pharmacogenomics. 2004; 5:433-38.

27. Li M, Copeland A, Han J. DUK-A Fast and Efficient Kmer Based Sequence Matching Tool. 2011.

28. Gnerre S, MacCallum I, Przybylski D, Ribeiro FJ, Burton JN, Walker BJ, Sharpe T, Hall G, Shea TP, Sykes S, Berlin AM, Aird D, Costello M, Daza R, Williams L, Nicol R, Gnirke A, Nusbaum C, Lander ES, Jaffe DB. High-quality draft assemblies of mammalian genomes from massively parallel sequence data. PNAS. 2011; 108:1513-8

29. Hyatt D, Chen G-L, LoCascio PF, Land ML, Larimer FW, Hauser L. Prodigal: prokaryotic gene recognition and translation initiation site identification. BMC Bioinformatics. 2010; 11:119.

30. Mavromatis K, Ivanova NN, Chen I-MA, Szeto E, Markowitz VM, Kyrpides NC The DOE-JGI standard operating procedure for the annotations of microbial genomes. Stand Genomic Sci. 2009; 1:63-7.

31. Pati A, Ivanova NN, Mikhailova N, Ovchinnikova G, Hooper SD, Lykidis A, Kyrpides NC. GenePRIMP: a gene prediction improvement pipeline for prokaryotic genomes. Nat Meth. 2010; 7:455-7.

32. Markowitz VM, Mavromatis K, Ivanova NN, Chen I-MA, Chu K, Kyrpides NC. IMG ER: a system for microbial genome annotation expert review and curation. Bioinformatics. 2009; 25:2271-78.

33. DeAngelis KM, D'Haeseleer P, Chivian D, Fortney JL, Khudyakov J, Simmons B, Woo H, Arkin AP, Davenport K, Goodwin L, Chen A, Ivanova N, Kyrpides NC, Mavromatis K, Woyke T, Hazen TC. Complete genome sequence of "Enterobacter lignolyticus" SCF1. Stand Genomic Sci. 2011; 5:69-85.

34. Borglin S, Joyner D, Jacobsen J, Mukhopadhyay A, Hazen TC. Overcoming the anaerobic hurdle in phenotypic microarrays: Generation and visualization of growth curve data for Desulfovibrio vulgaris Hildenborough. J Microbiol Methods. 2009; 76:159-68.

35. Woo HL, Hazen TC, Simmons BA, DeAngelis KM. Enzyme activities of aerobic lignocellulolytic bacteria isolated from wet tropical forest soils. Syst Appl Microbiol. 2014; 37:60-7.

36. Masai E, Katayama Y, Nishikawa S, Fukuda M. Characterization of Sphingomonas paucimobilis SYK-6 genes involved in degradation of lignin-related compounds. J Ind Microbiol Biotech. 1999; 23:364-73.

37. Bugg TDH, Ahmad M, Hardiman EM, Rahmanpour R. Pathways for degradation of lignin in bacteria and fungi. Nat Prod Rep. 2011; 28:1883-96

38. Masai E, Katayama Y, Fukuda M. Genetic and biochemical investigations on bacterial catabolic pathways for lignin-derived aromatic compounds. Biosci Biotechnol Biochem. 2007; 71:1-15.

39. Peng R-H, Xiong A-S, Xue Y, Fu X-Y, Gao F, Zhao W, Tian Y-S, Yao Q-H. Microbial biodegradation of polyaromatic hydrocarbons. FEMS Microbiol Rev. 2008; 32:927-55.

40. DeAngelis KM, Sharma D, Varney R, Simmons B, Isern NG, Markilllie LM Nicora C, Norbeck AD, Taylor RC, Aldrich JT, Robinson EW. Evidence supporting dissimilatory and assimilatory lignin degradation in Enterobacter lignolyticus SCF1. Front Microbiol. 2013; 4:280.

41. Miller GL. Use of dinitrosalicylic acid reagent for determination of reducing sugar. Anal Chem. 1959; 31:426-28.

42. Khudyakov JI, D'haeseleer P, Borglin SE, DeAngelis KM, Woo H, Lindquist EA, Hazen TC, Simmons BA, Thelen MP. Global transcriptome response to ionic liquid by a tropical rain forest soil bacterium, Enterobacter lignolyticus. PNAS. 2012; 109:E2173-82.

doi:10.1186/1944-3277-9-19

Cite this article as: Woo et al:: Complete genome sequence of the lignin-degrading bacterium Klebsiella sp. strain BRL6-2. Standards in Genomic Sciences 2014 9:19.

\section{Submit your next manuscript to BioMed Central and take full advantage of:}

- Convenient online submission

- Thorough peer review

- No space constraints or color figure charges

- Immediate publication on acceptance

- Inclusion in PubMed, CAS, Scopus and Google Scholar

- Research which is freely available for redistribution 